\title{
Sensitization of Psychomotor Stimulation and Conditioned Reward in Mice: Differential Modulation by Contextual Learning
}

\author{
Andy N Mead*,1,2, Hans S Crombag*, ${ }^{*, 2}$ and Beatriz A Rocha ${ }^{1,3}$ \\ 'Behavioural Neuroscience Branch, The National Institute on Drug Abuse, Intramural Research Program, Baltimore, MD, USA
}

\begin{abstract}
Incentive motivation theory ascribes a critical role to reward-associated stimuli in the generation and maintenance of goal-directed behavior. Repeated psychomotor stimulant treatment, in addition to producing sensitization to the psychomotor-activating effects, can enhance the incentive salience of reward-associated cues and increase their ability to influence behavior. In the present study, we sought to investigate this incentive sensitization effect further by developing a model of conditioned reinforcement (CR) in the mouse and investigating the effects of a sensitizing treatment regimen of amphetamine on CR. Furthermore, we assessed the role of contextual stimuli in amphetamine-induced potentiation of CR. We found that mice responded selectively on a lever resulting in the presentation of a cue previously associated with $30 \%$ condensed milk solution, indicating that the cue had attained rewarding properties. Prior treatment with amphetamine $(4 \times 0.5 \mathrm{mg} / \mathrm{kg}$ i.p.) resulted in psychomotor sensitization and enhanced subsequent responding for the CR. Furthermore, this enhancement of responding for the cue occurred independent of the drug-paired context, whereas the sensitized locomotor response was only observed when mice were tested in the same environment as that in which they had received previous amphetamine. These results demonstrate that the CR paradigm previously developed in the rat can be successfully adapted for use in the mouse, and suggest that behavioral sensitization to amphetamine increases the rewarding properties (incentive salience) of rewardpaired cues, independent of the drug-paired context.

Neuropsychopharmacology (2004) 29, 249-258, advance online publication, 27 August 2003; doi: I0.1038/sj.npp. 1300294
\end{abstract}

Keywords: amphetamine; conditioning; reinforcer; locomotor activity; cues; drug addiction

\section{INTRODUCTION}

The ability of a conditioned (or secondary) reinforcer (CR) to support acquisition of novel instrumental responding has been used extensively to study the neurobiological processes underlying reward (Robbins, 1976; Mackintosh, 1983). In this model, rats learn to respond on a lever that produces a cue, which was previously presented in association with a natural reward, such as food or water. Thus, lever-pressing behavior is maintained solely by the learned (or conditioned) reinforcing properties of the cue.

\footnotetext{
*Correspondence: Dr A Mead, Laboratory of Experimental Psychology, School of Biological Sciences, The University of Sussex, Falmer, Brighton BNI 9QG, UK, Tel: + 1273 877052, Fax: + 1273 6786II, E-mail: andym@biols.susx.ac.uk. Dr H Crombag, Department of Psychology, The University of Michigan, Ann Arbor, MI 48109-II09, E-mail: hcrombag@umich.edu

${ }^{2}$ These authors contributed equally to this work.

${ }^{3}$ Present address: Department of Pharmacology, Merck Research Laboratories, Rahway, NJ 07065, USA.

Received 2I March 2003; revised I 8 July 2003; accepted 22 July 2003 Online publication: 23 July 2003 at http://www.acnp.org/citations/ NPP07230303122/default.pdf
}

There are a number of reports demonstrating that various direct and indirect acting dopamine (DA) agonists potentiate responding on a lever that produces a conditioned reinforcer (the CR lever). Amphetamine, for instance, administered systemically or directly into the nucleus accumbens potently increases responding on the $\mathrm{CR}$ lever, without affecting responding on a lever not associated with reward (the NCR lever) (Robbins, 1976; Taylor and Robbins, 1984; Cador et al, 1989; Kelley and Delfs, 1991a, b; Parkinson et al, 1999; Everitt et al, 2000). In turn, both DA D1- (SCH23390) and D2-type (raclopride) receptor antagonists attenuate responding for a CR (Cador et al, 1991; for a review, see Sutton and Beninger, 1999) and reduce the reward potentiating effects of amphetamine (Wolterink et al, 1993). Together, these findings demonstrate a critical role of the nucleus accumbens DA system in CR and the acute potentiating effects of amphetamine. Brain areas other than the nucleus accumbens have also been implicated, including the basolateral amygdala (Cador et al, 1989), ventral subiculum (Burns et al, 1993; Hitchcott and Phillips, 1997), and subthalamic nucleus (Baunez et al, 2002).

Little is known about the effects of repeated (chronic) drug treatment on responding for a CR. This is surprising 
because the rewarding effects of amphetamine show sensitization with repeated treatment as indicated by the acquisition of a drug self-administration habit (Piazza et al, 1989; Horger et al, 1992), responding under a progressive ratio schedule of reinforcement (Mendrek et al, 1998; Vezina et $a l, 2002$ ) and the development of conditioned place preference (Lett, 1988). Taylor and Horger (1999) reported that animals sensitized to cocaine showed potentiated responding on the CR lever relative to control animals, and this finding is consistent with an earlier report showing potentiated lever responding by amphetamine in animals pretreated with morphine (Cunningham and Kelley, 1992). More recently, Wyvell and Berridge (2001) using a Pavlovian-to-instrumental transfer (PIT) procedure, reported enhanced reward seeking elicited by noncontingently presented reward-associated stimuli in amphetamine pre-exposed rats compared to control animals.

The purpose of the present study was two-fold. Initially we aimed to characterize drug effects on CR in mice. So far, this model has only been studied in rats, and in light of growing interest in using transgenic and knockout mice to understand genetic influences in drug abuse, it is important to characterize similar procedures in mice. In addition, we aimed to investigate the impact of sensitization-related neuroplastic changes on CR further by examining the ability of contextual stimuli to modulate the effects of repeated drug treatment on CR. That is, it is well known that repeated treatment with amphetamine may induce neuroplastic changes underlying sensitization, but whether sensitization is expressed behaviorally is often dependent on the environmental context (Post et al, 1987; Anagnostaras and Robinson, 1996; Battisti et al, 1999). This phenomenon is well characterized using stimulant-induced psychomotor activation but little is known about the ability of the context to modulate the rewarding effects of drugs of abuse.

\section{METHODS}

\section{Subjects}

A total of 24 C57BL/6J mice (Jackson Laboratory, Maine, USA) were housed in groups of two to four, and allowed at least 1 week of habituation to the holding room prior to the beginning of the experiment. Food (Purina Rodent Chow) and water were continuously available in their home cage but not during experimental sessions. Mice were maintained on a 12/12 h light-dark cycle (light on from 0700 to 1900) and all experimental sessions were conducted during the light phase.

\section{Drugs}

All injections were administered at a volume of $10 \mathrm{ml} / \mathrm{kg}$ i.p. D-amphetamine (AMPH) sulfate was dissolved in $0.9 \%$ saline, and doses were expressed as base weight of drug.

\section{Apparatus}

Operant chambers. Standard mouse operant chambers (Med Associates, Inc., Georgia, VT) were used containing a front hinged loading door, acrylic side panels, and a stainless-steel back panel $(21.59 \times 17.78 \times 12.70 \mathrm{~cm})$. The chambers were located in sound- and light-attenuating cabinets equipped with fans that provided ventilation and low-level background noise. The side panel of each chamber contained a liquid dipper that delivered milk into an aperture located between two ultrasensitive mouse levers. A sensor located in the delivery aperture monitored nose-pokes into the liquid dipper and a $3 \mathrm{~W}$ stimulus light was located directly above each of the levers (Arroyo et al, 1998). Finally, along the long side of the operant chamber two parallel positioned sets of infrared photocells were mounted (spaced $4 \mathrm{~cm}$ apart), which measured locomotor activity (crossovers). During the sensitization phase of the experiment, the operant chambers provided the Paired context (see below).

Activity monitors. Digiscan mouse activity monitors (Accuscan Instruments, Inc., Ohio) measuring approximately $24.5 \times 24.5 \times 31 \mathrm{~cm}$ were located inside sound- and light-attenuating chambers containing fans that provided ventilation and low-level background noise. Horizontal activity was monitored by 16 infrared sensors located approximately $2.5 \mathrm{~cm}$ above the floor, along the perimeter of the activity monitor (each axis had eight pairs of photocells spaced $2.5 \mathrm{~cm}$ apart). During the sensitization phase of the experiment, the activity monitor provided the Unpaired context (see below).

\section{Procedure}

The experiment was conducted over a 26-day period consisting of the following three phases:

Phase 1: Pavlovian conditioning. In order to learn to associate a stimulus-light with the delivery of a primary reward, mice underwent three, 40-min conditioning sessions per day, each separated by a 10 -min intermission. The house light was turned off during the session and turned on during the intermission. Each session started with the presentation of a compound conditioned stimulus (or CS) that consisted of a 10-s flashing of two stimulus lights and the sound of the dipper mechanism. The CS was presented on a variable-interval 90 -s schedule (ie one presentation of the CS occurred on average every $90 \mathrm{~s}$, but the actual time between CS presentations varied between 30 and $150 \mathrm{~s}$ ). At $5 \mathrm{~s}$ following the onset of the CS the liquid dipper was activated, delivering $0.01 \mathrm{ml}$ of $30 \%$ condensed milk solution (the unconditioned stimulus or US). After a further $5 \mathrm{~s}$, the dipper retracted and the CS terminated. For each session, the total number of nose-pokes occurring during the CS presentation, expressed as a percentage of total nosepokes during the session (CS\%), and the latency to nosepoke following the CS onset (retrieval latency) were recorded. The training phase continued until performance remained stable (ie no significant effect of Session as determined by analysis of variance (ANOVA)). In addition, locomotor crossover activity (interruption of the two photobeams consecutively) was quantified for each conditioning session. The levers were removed from the chamber during this phase of the experiment.

Phase 2: induction of sensitization. Following conditioning, mice were randomly assigned to one of three treatment 
groups ( $n=8$ per group), all of which received two i.p. injections each day (separated by a minimum of $90 \mathrm{~min}$ ) on 4 consecutive days. The Paired group received an injection of $0.5 \mathrm{mg} / \mathrm{kg}$ AMPH prior to being placed into the operant chambers, and an injection of vehicle (saline) prior to being placed into the activity monitors. Thus, for this group AMPH treatments were explicitly paired with the context of the operant chamber. The Unpaired group received an injection of AMPH prior to being placed into the activity monitor and an injection of saline prior to being placed in the operant chamber. Thus for this group AMPH treatments were explicitly unpaired with the operant chamber. Finally, the Control group received two injections of saline, one prior to being placed in the operant chamber and one prior to being placed in the activity monitor. For each group the order of treatments was counterbalanced such that some mice received the injection in the operant chambers first and then the injection in the activity monitors, and vice versa. Locomotor crossover activity was recorded in 3-min intervals for a total of $60 \mathrm{~min}$ postinjection. The levers were removed from the apparatus during this phase of the experiment. The day following the last pretreatment injection, one additional Pavlovian conditioning session (session 9) was conducted using the procedures described above in order to evaluate the extent to which repeated treatment with amphetamine or saline influenced Pavlovian conditioning performance (Harmer and Phillips, 1998; Taylor and Jentsch, 2001).

Phase 3: testing for CR. For this phase of the experiment the levers were inserted into the operant chambers. Responding on one lever resulted in the presentation of the CS (CR lever) and responding on the second lever had no programmed consequences (NCR lever). Note that during this phase of the experiment, mice were tested under extinction conditions and no milk reward was present. The test session began once the mouse had emitted three responses on the $\mathrm{CR}$ lever and subsequently lasted for $60 \mathrm{~min}$. This beginning-of-session criterion was used because amphetamine produced a clear effect on the latency to initiate responding (see Results). If the mouse did not respond three times within a 120-min period, the session began automatically (thus, the maximum session duration was $180 \mathrm{~min})$. Responding on the two levers was recorded to determine whether the CR was capable of supporting selective operant lever-pressing behavior.

As the effects of sensitization on psychomotor activation and reward measures are typically dose dependent (Vezina et al, 2002), we constructed a full within-subjects doseeffect function. Prior to the first and second test sessions, mice received an i.p. injection of saline or $0.5 \mathrm{mg} / \mathrm{kg} \mathrm{AMPH}$ in a counterbalanced order. Prior to the third test session, all mice received an injection of $1.0 \mathrm{mg} / \mathrm{kg} \mathrm{AMPH}$, and prior to the fourth session all mice received an injection of $1.5 \mathrm{mg} / \mathrm{kg}$ AMPH. This injection scheme was used in order to minimize sensitization effects produced by administering multiple challenge injections to the same mouse. At the end of the experiment, a final (fifth) session was conducted, during which all mice received an injection of saline. In order to maintain the behavior over the course of the five test sessions, the sessions occurred at 2-day intervals, and
Pavlovian reconditioning sessions were conducted on each of the intervening days using the same procedures as described under phase 1 .

\section{Statistical Analysis}

The data collected from phase 1 (CS\%, retrieval latency and locomotor activity) were subjected to a two-way mixedfactor ANOVA with Group and Session as factors. To determine the stability of performance on these measures, analysis of sessions five to eight was also performed independently. To determine whether repeated treatments with amphetamine $v s$ saline (phase 2) produced differences in Pavlovian conditioning performance, the results from the final conditioning session of phase 1 (session 8) were compared to the results from conditioning session 9 conducted immediately following the sensitization phase (phase 2), using paired $t$-tests. Where applicable, betweengroup comparisons were performed for session 9 using oneway ANOVA.

The data collected from phase 2 were subjected to twoway mixed factor ANOVA with Session and Group as factors. As the measurement of horizontal crossover activity was different for the activity monitor and the operant chambers (the activity monitors used eight photobeams, while the operant chambers used two photobeams), independent analyses were performed for each environmental context. Behavioral sensitization was defined as a significant increase in activity from sessions 1 to 4 , as determined by Dunnett's post hoc comparisons following one-way ANOVA for each group. In order to compare the rate of sensitization between the two contexts, linear regression analysis was performed and differences in slope coefficients were tested for significance using an analysis of covariance (ANCOVA). Sensitization is indicated by a positive slope (slope coefficient $>0$ ), and the greater the slope coefficient, the greater the rate of sensitization (Badiani et al, 1995; Crombag et al, 1999; Mead et al, 2002).

The data collected from phase 3 were subjected to threeway mixed-factor ANOVA with Dose, Lever (CR vs NCR), and Group as factors. Activity (during the first $60 \mathrm{~min}$ ) and the latency to initiate responding were analyzed using a two-way mixed-factor ANOVA with Dose and Group as factors. Following significant main-effects or interactions, post hoc comparisons were performed using Dunnett's (comparisons to saline) or Student-Newman-Keuls (comparisons between groups) test following one-way ANOVA.

\section{RESULTS}

\section{Phase 1: Pavlovian Conditioning}

A total of eight conditioning sessions were conducted prior to phase 2 of the study. Over the course of these eight sessions, the mean retrieval latency to access the fooddelivery aperture following CS onset (Figure 1a) significantly decreased until performance stabilized at around $5 \mathrm{~s}$, that is, the time of US presentation (main-effect of Session; $\left.\mathrm{F}_{7,147}=83.7, p<0.01\right)$. There were no differences between the three experimental groups (Session by Group interaction; $\mathrm{F}_{14,147}=0.9$, NS). Similarly, the percentage of total food-delivery aperture entries during the CS presentation 
a

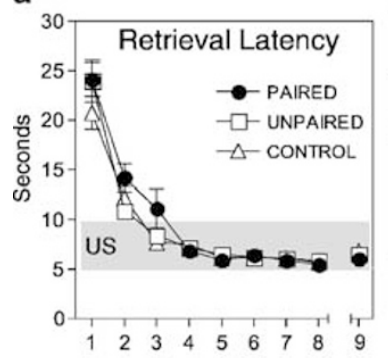

b

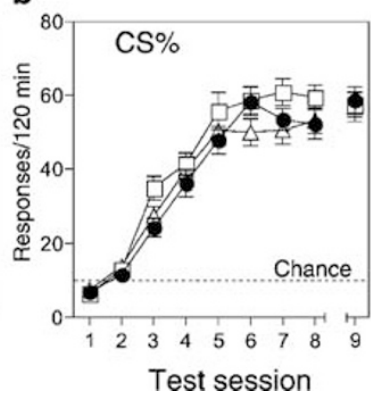

C

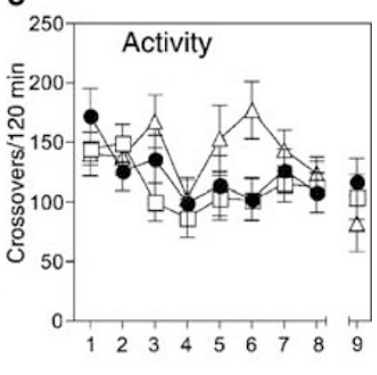

Figure I Behavior during eight consecutive Pavlovian conditioning sessions (phase I) and a postsensitization phase session (session 9) during which mice were conditioned to associate a 5 s compound CS (shaded area) with the delivery of the milk reward. (a) The mean ( \pm SE) retrieval latency to access the milk-delivery aperture following CS presentation reached stable performance from sessions 4 to 5 onward and there were no significant differences between groups. The sensitization treatment phase produced a small change in retrieval latency but no group differences. (b) The mean ( \pm SE) number of total fooddelivery aperture entries during CS presentation as a percentage of total aperture entries (CS\%) reached stable performance from session 5 onwards and there were no between-group differences. The sensitization treatment phase produced no change in CS\% and no group differences. (c) Mean (spontaneous) number of ( \pm SE) crossovers did not differ as a function of session or group before or after the sensitization treatment phase.

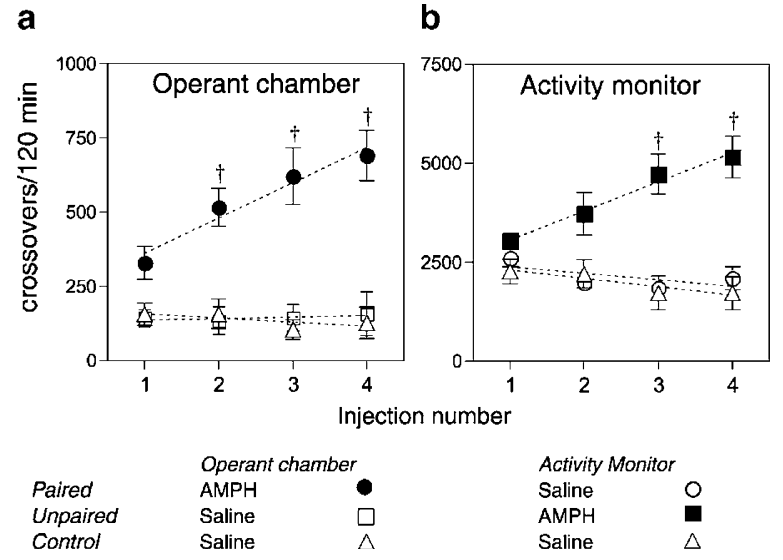

C

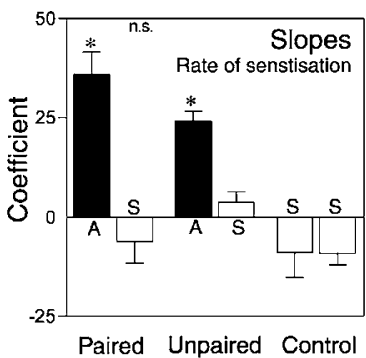

Paired Unpaired Control

Unpaired

$\begin{array}{lll}\text { Saline } & \\ \text { Saline } & \wedge\end{array}$

Saline

Saline

Figure 2 Behavior in response to four consecutive injections of AMPH and Saline (phase 2) administered in the operant chambers (a) and the activity monitors (b). Repeated amphetamine administration produced a progressive increase in the mean ( \pm SE) number of locomotor crossover activity in the operant chambers (Paired group) and the activity monitor (Unpaired group). Repeated injections of saline produced a small increase in the Unpaired group and only marginal changes in locomotor crossover activity in all other groups. (c) Analyses of the calculated slope coefficients confirmed a significant increase in amphetamine-induced locomotor crossover activity in the Paired and the Unpaired group, and there were no differences in the rate of sensitization between these groups. Asterisks and swords denote an effect of Group and Sessions, respectively.

(CS\%, Figure 1b) increased over sessions (main effect of Session; $\left.\mathrm{F}_{7,147}=106.0, p<0.01\right)$. Again, stable performance was attained from session 5 onwards, and there were no between-group differences (Session by Group interaction; $\left.\mathrm{F}_{7,147}=0.8, \mathrm{NS}\right)$. An ANOVA conducted on the data from sessions 5 to 8 for retrieval latency and CS\% revealed no effect of Session, indicating stable performance.

Following the sensitization phase of the experiment, there were no significant changes in $\operatorname{CS} \%\left(t_{23}=-1.3, \mathrm{NS}\right.$, Figure $1 \mathrm{~b})$ or activity $\left(t_{23}=0.8, \mathrm{NS}\right.$, Figure $\left.1 \mathrm{c}\right)$ during the subsequent conditioning session (compare session 8 with session 9). There was, however, a small but significant increase in the retrieval latency to access the milk delivery aperture (compare session 8 with session 9, Figure 1a; $\left.t_{23}=4.8, p<0.01\right)$, but no difference between groups was evident $\left(\mathrm{F}_{2,21}=1.21, \mathrm{NS}\right)$. Thus, the pretreatment phase of the experiment produced a small change in the discriminated approach behavior in response to the CS, but this change occurred irrespective of whether mice had received AMPH or saline in phase 2. No differences in CS\% or retrieval latency were observed during any of the Pavlovian reconditioning sessions.

Analysis of activity levels during training (Figure 1c) revealed no significant between-group differences (maineffect of Group; $F_{2,21}=0.5$, NS, Session by Group interaction; $\mathrm{F}_{7,147}=1.39$, NS).

\section{Phase 2: Induction of Sensitization}

The locomotor crossover response in the operant chambers (Paired context) to four intermittent treatments with AMPH or saline is shown in Figure 2a. An ANOVA revealed a significant Group by Session interaction $\left(\mathrm{F}_{6,63}=13.0\right.$, $p<0.01)$. Subsequent one-way ANOVAs revealed a maineffect of Session in the amphetamine treated Paired group $\left(\mathrm{F}_{3,21}=18.4, p<0.01\right)$. Thus, repeated injections of AMPH produced a progressive increase, that is, sensitization, of locomotor crossover activity. Post hoc tests indicated significant behavioral increases in activity during sessions 2-4 relative to the response to the first injection of 
amphetamine $\left(t_{21}=3.59,5.61\right.$, and 6.96, respectively, $p<0.01)$. No significant effect of Session was evident for the Unpaired (Figure 2a) and Control group receiving repeated injections of saline in the operant chambers.

The locomotor crossover response in the activity monitors (Unpaired context) to four intermittent treatments with AMPH or saline is shown in Figure 2b. ANOVA revealed a significant Group by Session interaction $\left(\mathrm{F}_{6,63}=12.1, p<0.01\right)$. Subsequent one-way ANOVAs revealed a main-effect of Session in the AMPH-treated Unpaired group, which reached significance during sessions 3 and 4, relative to session $1 \quad\left(t_{21}=3.80\right.$ and 4.77, respectively, $p<0.01)$. Furthermore, a significant effect of Session was evident for the Paired (Figure 2b) and Control groups receiving repeated injections of saline in the activity monitors, indicative of habituation to this environment $\left(\mathrm{F}_{3,21}=7.99, p<0.01\right.$ and $\mathrm{F}_{3,21}=5.43, p<0.01$, respectively).

Linear regression analysis showed a significant increase in locomotor crossover activity over the four test sessions in both AMPH-treated groups; that is, the Paired group that received repeated injections of $\mathrm{AMPH}$ in operant chambers (mean slope coefficient $=35.93 \pm 5.670, \quad r^{2}=0.95$, $\left.\mathrm{F}_{1,30}=12.6, p<0.01\right)$ and the Unpaired group that received repeated injections of $A M P H$ in the activity chambers (mean slope coefficient $=24.10 \pm 2.443, \quad r^{2}=0.98$, $\left.\mathrm{F}_{1,30}=13.6, p<0.01\right)$. More importantly, follow-up ANCO$\mathrm{VA}$ analysis indicated that the calculated slope coefficients of the two groups did not differ $\left(F_{1,60}=0.96\right.$, NS). Thus, although the two environments yielded different activity measures, the relative increase in activity over sessions (ie the rate of sensitization) was the same for both the groups (Figure 2c).

\section{Phase 3: Testing for CR}

Conditioned reinforcement. The effects of AMPH on responding on the $\mathrm{CR}$ and NCR lever are shown in Figure $3 \mathrm{a}$ and $\mathrm{b}$, respectively. A three-way ANOVA for lever press behavior revealed a significant main-effect of Lever $\left(\mathrm{F}_{1,21}=83.4, p<0.01\right)$, indicating that mice responded more on the CR lever than the NCR lever. In addition, there were significant Dose by Lever $\left(\mathrm{F}_{4,84}=3.0, p<0.05\right)$, Dose by Group $\left(\mathrm{F}_{8,84}=2.0, \quad p<0.05\right)$, and Lever by Group $\left(\mathrm{F}_{2,21}=3.0, p<0.05\right)$ interactions. Post hoc investigation of these interactions revealed that during the first saline test, and following $0.5 \mathrm{mg} / \mathrm{kg} \mathrm{AMPH}$, both the Paired and Unpaired groups showed significantly more responses on the CR lever (Figure 3a), but not on the NCR lever (Figure $3 \mathrm{~b})$, relative to the Control group $(p<0.05)$. Furthermore, there were no differences between the Paired and Unpaired groups in responding on either the CR or NCR lever indicating that, irrespective of where the sensitizing regimen of AMPH was administered, prior experience with $\mathrm{AMPH}$ enhanced responding for the $\mathrm{CR}$ a

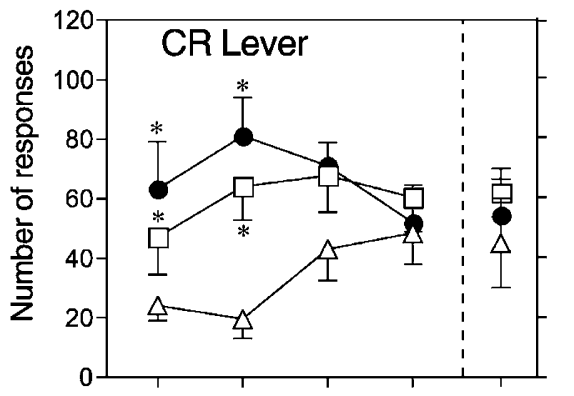

C

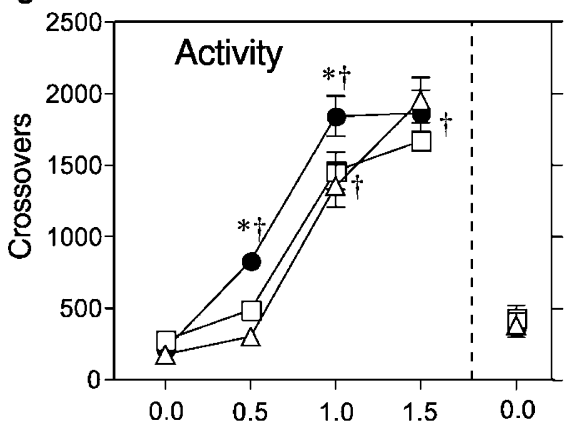

b

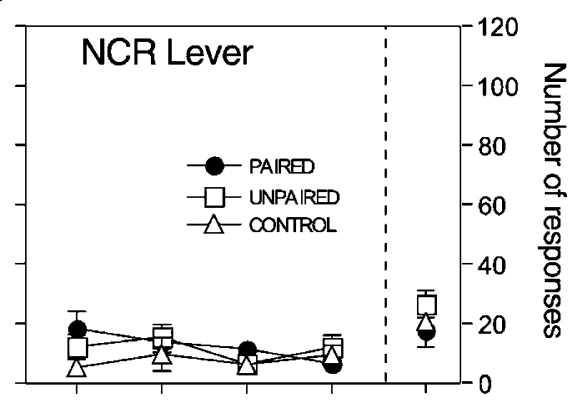

d

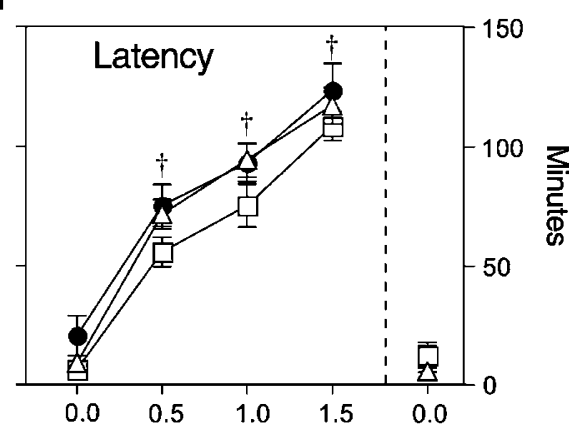

Amphetamine $(\mathrm{mg} / \mathrm{kg})$

Figure 3 Behavior during the CR test sessions (phase 3). (a) The mean ( \pm SE) number of responses on the lever producing the CR was increased in mice pretreated with AMPH in the operant chambers (Paired) or activity monitor (Unpaired), relative to mice pretreated with saline. No differences were observed during the final test session following challenge injections of saline. (b) The mean ( \pm SE) number of responses on the neutral lever (NCR) showed no differences between groups or challenge doses at any time. (c) The effect of AMPH on the mean ( \pm SE) number of locomotor crossovers during the CR test sessions. AMPH produced a dose-dependent increase in locomotor activity in all groups, but a markedly greater effect in the Paired group following challenge doses of 0.5 and $1.0 \mathrm{mg} / \mathrm{kg}$ amphetamine. No differences were evident between the Unpaired and Control groups and none of the groups differed following the injections of saline. (d) The effect of AMPH on the mean ( \pm SE) 'latency to initiate responding' during the CR test sessions. AMPH produced a dose-dependent increase in the latency to initiate responding in all groups and this effect of dose did not differ between groups. Asterisks and swords denote effects of group and dose, respectively. 
(Figure 3a). At doses of 1.0 and $1.5 \mathrm{mg} / \mathrm{kg} \mathrm{AMPH}$ there were no between-group differences for either lever. Analysis of Dose for each group indicated that there was no effect of the AMPH challenge injection in any of the groups, although the ANOVA results approached significance for the Control group $(p=0.08)$, due to the increase in responding observed following 1.0 and $1.5 \mathrm{mg} / \mathrm{kg}$. There were also no effects on NCR responses of any challenge dose of AMPH (Figure 3b).

Locomotor activity. The effect of AMPH on locomotor activity during the $\mathrm{CR}$ test sessions is shown in Figure 3c. A two-way ANOVA on the locomotor activity data during the $\mathrm{CR}$ test sessions revealed a significant main-effect of Dose $\left(\mathrm{F}_{4,84}=291.7, p<0.01\right)$ and a Dose by Group interaction $\left(\mathrm{F}_{8,84}=3.78, p<0.01\right)$. Further analysis of this interaction revealed that the Paired group displayed a significantly greater activity response to 0.5 and $1.0 \mathrm{mg} / \mathrm{kg}$ AMPH $(p<0.05)$ than either the Unpaired or Control groups. No differences were observed at other doses of AMPH, or between the Unpaired and Control groups.

The effect of AMPH on the latency to initiate responding during the CR test sessions is shown in Figure 3d. A twoway ANOVA revealed a main-effect of Dose $\left(\mathrm{F}_{4,84}=183.2\right.$, $p<0.01$ ), but no main-effect of Group or an interaction. Subsequent post hoc analysis indicated that AMPH increased the latency to initiate responding in a dosedependent manner in all groups $(p<0.01)$, and that this effect of AMPH did not differ between groups.

Finally, no significant between-group differences were observed in responding on the CR or NCR levers following the injection of saline administered at the end of the experiment (Figure $3 \mathrm{a}$ and $\mathrm{b}$ ), in locomotor activity (Figure 3c), or in the latency to begin responding (Figure 3d).

\section{DISCUSSION}

Using a model of CR in mice we report the following. First, the effects of prior treatment with amphetamine, which resulted in the development of robust psychomotor sensitization (ie a progressive increase in locomotor activity), did not affect Pavlovian approach behavior (ie appropriate responding in the presence of the primary reinforcer). Second, when mice were subsequently given the opportunity to respond on a lever for the reward-associated stimulus, they did so avidly, and those that had received prior amphetamine treatments responded at higher rates than mice that had received repeated saline treatments (in the absence of changes in responding on the neutral (NCR) lever). This effect was observed irrespective of the challenge dose of amphetamine given immediately prior to testing. Finally, while the expression of psychomotor sensitization was context specific, and seen only when amphetamine treatments had been paired with placement into the operant chambers, the effects of prior amphetamine experience on responding for $\mathrm{CR}$ were seen irrespective of the context in which amphetamine had previously been experienced.

At the outset, it should be emphasized that we used a within-group design in which each mouse received multiple challenge doses of amphetamine and multiple CR test sessions. Thus, some sensitization could have occurred as a result of repeated testing. For instance, the small increase in $\mathrm{CR}$ observed in the Control group at the end of the experiment may have been due to sensitization induced by the repeated challenge injections of amphetamine. Additionally, the repeated CR testing under nonreward conditions might have weakened the association between the light stimulus (the CR) and the milk reward (ie extinction). However, the Pavlovian reconditioning sessions prior to each CR test did not reveal group differences or differences from baseline.

\section{Sensitization of Psychomotor Activation}

Repeated intermittent amphetamine treatments induced robust psychomotor sensitization as indicated by a progressively greater locomotor crossover response to amphetamine over treatment sessions. Although amphetamine treatments produced a similar rate of sensitization in the Paired and Unpaired groups (the percent change in activity from sessions 1 to 4 was approximately $48 \%$ for the Paired group and 59\% for the Unpaired group), only mice that previously received injections paired with placement into the operant chambers expressed locomotor sensitization during the CR test sessions, as indicated by a shift to the left in the dose-effect function relative to saline pretreated animals. In other words, the expression of psychomotor sensitization was context specific. These findings are in accordance with a sizable literature demonstrating contextual modulation of the expression of psychomotor sensitization in rats (Mazurski and Beninger, 1987; Post et al, 1987; Stewart and Vezina, 1988; Vezina et al, 1989; Pert et al, 1990; Anagnostaras and Robinson, 1996; Carey and Gui, 1998) and in mice (Cabib, 1993; Tirelli and Terry, 1998; Battisti et al, 1999).

A thorough discussion of the phenomenon of contextdependent sensitization is beyond the scope of this report and we direct the reader to a number of excellent research reports and reviews that have been published (Post et al, 1987; Stewart and Badiani, 1993; Anagnostaras and Robinson, 1996). Two things are worth noting. First, clearly druginduced interoceptive cues were not sufficient to serve as contextual stimuli. Had this been the case, one would have expected the Paired and Unpaired groups to display similar levels of locomotor activity following amphetamine administration during the CR testing phase. Second, there were no group differences in the locomotor response to a challenge injection of saline, that is, there was no conditioned locomotor response in the Paired group; which was likely due to the extensive pre-exposure to the operant chambers during the first phase of training (latent inhibition). It has been argued, for example, that behavioral sensitization is context specific because environmental stimuli acquire excitatory $\mathrm{CS}^{+}$properties, producing a progressively increasing conditioned response that adds to the unchanging unconditioned psychomotor drug effect (Tilson and Rech, 1973; Hinson and Poulos, 1981; Pert et al, 1990). This 'simple' excitatory conditioned model of sensitization clearly does not suffice here (Anagnostaras and Robinson, 1996; Martin-Iverson and Fawcett, 1996; Carey and Gui, 1998; Crombag et al, 2000; Hotsenpiller and Wolf, 2002), suggesting that more complex associative-learning 
processes are involved (Bouton, 1991; Holland, 1992; Anagnostaras and Robinson, 1996).

\section{Sensitization of CR}

When mice were given the opportunity to lever press for the stimulus light previously associated with milk reward, they did so avidly, and lever responding in all groups was highly selective for the CR lever; thus indicating that the stimulus served as a conditioned reward (Sutton and Beninger, 1999). More importantly, prior treatment with amphetamine produced a large increase in responding for the CR while having no discernable effect on responding on the NCR lever. This sensitization-dependent increase in CR was seen under drug-free conditions (saline challenge) and following the challenge injection of $0.5 \mathrm{mg} / \mathrm{kg}$ amphetamine, but not following the higher challenge doses of amphetamine (1.0 or $1.5 \mathrm{mg} / \mathrm{kg}$ ) in part due to the (nonsignificant) increase in responding observed following 1.0 and $1.5 \mathrm{mg} / \mathrm{kg}$ amphetamine in the Control group.

These findings extend previous studies in rats showing that cocaine or morphine pretreatment sensitizes amphetamine-induced potentiation of CR (Cunningham and Kelley, 1992; Taylor and Horger, 1999). However, two discrepancies with these previous reports are apparent. First, in saline pretreated mice, acute injections of amphetamine did not significantly increase responding for the $\mathrm{CR}$ at any challenge dose tested. It is not clear why this occurred, but it may be that the C57BL/6J mouse is relatively insensitive to the acute $\mathrm{CR}$ rate-increasing effects of amphetamine. Also, in previous studies rats were fooddeprived, which may have potentiated the acute effects of amphetamine on CR. Lastly, in these previous studies, amphetamine challenge injections were administered directly into the nucleus accumbens rather than systemically and this would have produced more potent actions at the neural target and fewer nonspecific actions.

The second discrepancy is that in amphetamine preexposed mice, none of the amphetamine challenge injections potentiated $\mathrm{CR}$ responding beyond that seen in drug-free animals, that is, following the saline challenge injection. A possible explanation for this lack of a dosedependent increase in $\mathrm{CR}$ responding could be that the amphetamine challenge injections produced behaviors that interfered with responding for the CR, as evidenced by the increase in the latency to begin responding. For instance, the dose-dependent increase in psychomotor activation could have disrupted lever-pressing behavior.

Along similar lines, Wyvell and Berridge (2001), using a PIT procedure, reported that sensitized female rats showed enhanced responding during noncontingent presentations of a reward-associated stimulus (incentive sensitization) but that challenge injections of amphetamine into the accumbens similarly did not further increase this effect. These authors attributed their finding to the amphetamine challenge injections producing magnified versions of Pavlovian-conditioned behaviors, such as approach, orienting, and sniffing, which interfered with lever pressing behavior (Tomie, 1996). Unfortunately, in the present experiment we did not measure similar types of behaviors during the CR test sessions, but on separate test sessions, we found that sensitization did not affect Pavlovian approach behaviors in the presence of the primary reinforcer (session 9), as indicated by CS\% and retrieval latency.

At first sight, such an absence of a sensitization effect on Pavlovian conditioning performance appears at odds with reports by others showing potentiation as a function of prior amphetamine, cocaine, or MDMA experience (Harmer and Phillips, 1998, 1999; Taylor and Jentsch, 2001). An important difference is, however, that in previous studies Pavlovian conditioning occurred after the sensitization treatment phase while in the present study training was conducted prior to amphetamine sensitization. Thus, psychostimulant sensitization likely affects the acquisition of Pavlovian-conditioned responses, rather than their later expression (Taylor and Jentsch, 2001). Whatever the case, our findings are consistent with the growing evidence that appetitive Pavlovian conditioning vs CR (vs PIT) are dependent on different substrates that can be dissociated genetically (Mead and Stephens, 2003) or by lesioning procedures (Parkinson et al, 1999; Everitt et al, 2000).

In contrast to psychomotor activation, sensitization of CR was expressed irrespective of whether mice had been sensitized in the operant chambers (Paired group) or in a different context (Unpaired group) at every challenge dose (saline or amphetamine) administered. It is possible that this lack of context dependency also resulted from the response-inhibiting effects of amphetamine-induced psychomotor activity on responding for the CR. As amphetamine produced greater psychomotor activity in the Paired group, this may have interfered with and reduced CR responding. This idea is particularly pertinent to the issue of contextual modulation because drug-like conditioned effects typically follow a relatively short time course that rapidly decays following exposure to the environmental CSs (Badiani et al, 1995; Crombag et al, 2000). To the extent that contextual modulation of sensitization mimics the time course of traditional conditioned responses, this could explain the relative context dependency of psychomotor sensitization expressed during the first hour of testing, and the relative context independency of sensitization of CR responding seen during the remainder of the test session. However, at least for psychomotor stimulant effects, this may not to be the case (Anagnostaras and Robinson, 1996).

Alternatively, we should consider the possibility that psychomotor sensitization and sensitization of CR are, in fact, differentially sensitive to contextual modulation. Although this idea will remain speculative at this time, demonstrations that different, albeit overlapping neural substrates mediate psychomotor activation $v s$ CR do permit such a scheme. While the nucleus accumbens appears critical for the locomotor effects of psychomotor stimulant drugs in sensitized and nonsensitized animals (Kelly, 1978; Paulson and Robinson, 1991), and for the effects of amphetamine on CR (Burns et al, 1993; Parkinson et al, 1999; Taylor and Horger, 1999; Everitt et al, 2000), the basolateral subdivision of the amygdala (BLA) appears to be selectively involved in CR (Burns et al, 1993). The involvement of the BLA in amphetamine-induced locomotor activity and sensitization to these effects seems, at best, controversial (Burns et al, 1993; Wolf et al, 1995; O’Dell et al, 1999; Bjijou et al, 2002). Furthermore, we have reported that 
the neural mechanisms underlying the ability of contextual CSs to act as incentive stimuli differ from those underlying the effects of contextual CSs on locomotor activity (Mead et al, 1999), specifically regarding glutamatergic transmission in the prefrontal cortex and the amygdala.

It is interesting, therefore, that repeated amphetamine injections given in the home cage enhance extracellular levels of DA in the amygdala (presumably BLA) elicited by reward-paired cues, even when presented in a different environment (Harmer and Phillips, 1999), indicating that the sensitized DA response in the amygdala can occur relatively independent of the drug-paired contextual stimuli. In contrast, sensitization-related increases in DA levels in the nucleus accumbens are markedly reduced when rats are tested in a nondrug paired context (Duvauchelle et al, 2000a, b). This may explain our behavioral differences showing that sensitization-induced enhancement of responding for a CR (a task dependent on the BLA) is relatively context insensitive, while sensitization-induced enhancement of locomotor activity (a behavior dependent on the nucleus accumbens) is strongly context dependent.

\section{Conclusions}

Understanding the biopsychological processes by which reward-associated cues trigger and maintain goal-directed behavior is critical for understanding motivation in general, and pathological states of motivation such as drug addiction. As stated recently by Robinson and Berridge (2003), 'a major question [in addiction] that is only beginning to be addressed is how the focus of sensitized reward value becomes directed to one particular target, such as taking drugs' ( $\mathrm{p} 41$ ). The present experiment provides a first exploration into how drug-experience-dependent neuroplastic changes (sensitization) and contextual stimuli interact to modulate incentive motivational processes. Although our results provide no simple answers, they illustrate at a behavioral level that the mechanisms involved in the expression of incentive sensitization may be distinct from those involved in the behavioral expression of other drug-experience-dependent neuroplastic changes such as psychomotor sensitization. This is particularly important because for some time, the belief has been that psychomotor stimulant actions and rewarding actions of addictive drugs are homologous and derive from the same biological mechanisms (Wise and Bozarth, 1987). Of course, the next challenge will be to parse out further the component psychological processes involved in the rewarding actions of drugs and determine how drug-experience and environment interact to influence these and their underlying neurobiological mechanisms. By demonstrating and characterizing the CR procedure in mice, our results should provide helpful parametric information for future studies using transgenic and knockout mice directed at elucidating these mechanisms.

\section{ACKNOWLEDGEMENTS}

This research was supported by funding from the National Institute on Drug Abuse, Intramural Research program (NIDA/IRP) to Beatriz Rocha.

\section{REFERENCES}

Anagnostaras SG, Robinson TE (1996). Sensitization to the psychomotor stimulant effects of amphetamine: modulation by associative learning. Behav Neurosci 110: 1397-1414.

Arroyo M, Markou A, Robbins TW, Everitt BJ (1998). Acquisition, maintenance and reinstatement of intravenous cocaine selfadministration under a second-order schedule of reinforcement in rats: effects of conditioned cues and continuous access to cocaine. Psychopharmacology 140: 331-344.

Badiani A, Anagnostaras SG, Robinson TE (1995). The development of sensitization to the psychomotor stimulant effects of amphetamine is enhanced in a novel environment. Psychopharmacology 117: 443-452.

Battisti JJ, Chang CH, Uretsky NJ, Wallace LJ (1999). Sensitization of stereotyped behavior to amphetamine is context and response dependent. Pharmacol Biochem Behav 63: 263-269.

Baunez C, Amalric M, Robbins TW (2002). Enhanced food-related motivation after bilateral lesions of the subthalamic nucleus. $J$ Neurosci 22: 562-568.

Bjijou Y, De Deurwaerdere P, Spampinato U, Stinus L, Cador M (2002). D-amphetamine-induced behavioral sensitization: effect of lesioning dopaminergic terminals in the medial prefrontal cortex, the amygdala and the entorhinal cortex. Neuroscience 109: 499-516.

Bouton M (1991). Sources of relapse after extinction in pavlovian and instrumental learning. Clin Psychol Rev 11: 125-140.

Burns LH, Robbins TW, Everitt BJ (1993). Differential effects of excitotoxic lesions of the basolateral amygdala, ventral subiculum and medial prefrontal cortex on responding with conditioned reinforcement and locomotor activity potentiated by intra-accumbens infusions of D-amphetamine. Behav Brain Res 55: 167-183.

Cabib S (1993). Strain-dependent behavioural sensitization to amphetamine: role of environmental influences. Behav Pharmacol 4: 367-374.

Cador M, Robbins TW, Everitt BJ (1989). Involvement of the amygdala in stimulus-reward associations: interaction with the ventral striatum. Neuroscience 30: 77-86.

Cador M, Taylor JR, Robbins TW (1991). Potentiation of the effects of reward-related stimuli by dopaminergic-dependent mechanisms in the nucleus accumbens. Psychopharmacology 104: 377-385.

Carey RJ, Gui J (1998). Cocaine conditioning and cocaine sensitization: what is the relationship? Behav Brain Res 92: 67-76.

Crombag HS, Badiani A, Maren S, Robinson TE (2000). The role of contextual $v s$ discrete drug-associated cues in promoting the induction of psychomotor sensitization to intravenous amphetamine. Behav Brain Res 116: 1-22.

Crombag HS, Mueller H, Browman K, Badiani A, Robinson TE (1999). A comparison of two behavioral measures of psychomotor activation following intravenous amphetamine or cocaine: dose- and sensitization-dependent changes. Behav Pharmacol 10: $205-213$.

Cunningham ST, Kelley AE (1992). Evidence for opiate-dopamine cross-sensitization in nucleus accumbens: studies of conditioned reward. Brain Res Bull 29: 675-680.

Duvauchelle CL, Ikegami A, Asami S, Robens J, Kressin K, Castaneda E (2000a). Effects of cocaine context on NAcc dopamine and behavioral activity after repeated intravenous cocaine administration. Brain Res 862: 49-58.

Duvauchelle CL, Ikegami A, Castaneda E (2000b). Conditioned increases in behavioral activity and accumbens dopamine levels produced by intravenous cocaine. Behav Neurosci 114: $1156-1166$. 
Everitt BJ, Cardinal RN, Hall J, Parkinson JA, Robbins TW (2000). Differential involvement of amygdala subsystems in appetitive conditioning and drug addiction. In: Aggleton J (ed). The Amygdala. Oxford University Press: New York. pp 353-390.

Harmer CJ, Phillips GD (1998). Enhanced appetitive conditioning following repeated pretreatment with D-amphetamine. Behav Pharmacol 9: 299-308.

Harmer CJ, Phillips GD (1999). Enhanced dopamine efflux in the amygdala by a predictive, but not a non-predictive, stimulus: facilitation by prior repeated D-amphetamine. Neuroscience $\mathbf{9 0}$ 119-130.

Hinson RE, Poulos CX (1981). Sensitization to the behavioral effects of cocaine: modification by Pavlovian conditioning. Pharmacol Biochem Behav 15: 559-562.

Hitchcott PK, Phillips GD (1997). Amygdala and hippocampus control dissociable aspects of drug-associated conditioned rewards. Psychopharmacology 131: 187-195.

Holland PC (1992). Occasion setting in Pavlovian conditioning. In: Medlin DL (ed). The Psychology and Learning and Motivation. Academic Press: San Diego, CA. pp 69-125.

Horger BA, Giles MK, Schenk S (1992). Preexposure to amphetamine and nicotine predisposes rats to self-administer a low dose of cocaine. Psychopharmacology 107: 271-276.

Hotsenpiller G, Wolf ME (2002). Conditioned locomotion is not correlated with behavioral sensitization to cocaine: an intralaboratory multi-sample analysis. Neuropsychopharmacology 27: 924-929.

Kelley AE, Delfs JM (1991a). Dopamine and conditioned reinforcement. I. Differential effects of amphetamine microinjections into striatal subregions. Psychopharmacology 103: 187-196.

Kelley AE, Delfs JM (1991b). Dopamine and conditioned reinforcement. II. Contrasting effects of amphetamine microinjection into the nucleus accumbens with peptide microinjection into the ventral tegmental area. Psychopharmacology 103: 197-203.

Kelly PH (1978). Drug-induced motor behavior. In: Iverson LL, Iverson SD (eds). Handbook of Psychopharmacology. Plenum: New York. pp 195-331.

Lett BT (1988). Enhancement of conditioned preference for a place paired with amphetamine produced by blocking the association between place and amphetamine-induced sickness. Psychopharmacology 95: 390-394.

Mackintosh NJ (1983). Conditioning and Associative Learning. Oxford University Press: New York.

Martin-Iverson M, Fawcett S (1996). Pavlovian conditioning of psychomotor stimulant-induced behaviours: has convenience let us astray? Behav Pharmacol 7: 24-41.

Mazurski EJ, Beninger RJ (1987). Environment-specific conditioning and sensitization with (+)-amphetamine. Pharmacol Biochem Behav 27: 61-65.

Mead AN, Katz JL, Rocha BA (2002). Intravenous cocaine-induced activity in $\mathrm{A} / \mathrm{J}$ and $\mathrm{C} 57 \mathrm{BL} / 6 \mathrm{~J}$ mice: behavioral sensitization and conditioned activity. Neuropharmacology 42: 976-986.

Mead AN, Stephens DN (2003). Selective disruption of stimulusreward learning in glutamate receptor grial knock-out mice. J Neurosci 23: 1041-1048.

Mead AN, Vasilaki A, Spyraki C, Duka T, Stephens DN (1999). AMPA-receptor involvement in c-fos expression in the medial prefrontal cortex and amygdala dissociates neural substrates of conditioned activity and conditioned reward. Eur J Neurosci 11: 4089-4098.

Mendrek A, Blaha CD, Phillips AG (1998). Pre-exposure of rats to amphetamine sensitizes self-administration of this drug under a progressive ratio schedule. Psychopharmacology 135: 416-422.

O’Dell LE, Sussman AN, Meyer KL, Neisewander JL (1999). Behavioral effects of psychomotor stimulant infusions into amygdaloid nuclei. Neuropsychopharmacology 20: 591-602.
Parkinson JA, Olmstead MC, Burns LH, Robbins TW, Everitt BJ (1999). Dissociation in effects of lesions of the nucleus accumbens core and shell on appetitive pavlovian approach behavior and the potentiation of conditioned reinforcement and locomotor activity by D-amphetamine. J Neurosci 19: 2401-2411.

Paulson PE, Robinson TE (1991). Sensitization to systemic amphetamine produces an enhanced locomotor response to a subsequent intra-accumbens amphetamine challenge in rats. Psychopharmacology 104: 140-141.

Pert A, Post R, Weiss SR (1990). Conditioning as a critical determinant of sensitization induced by psychomotor stimulants. NIDA Res Monogr 97: 208-241.

Piazza PV, Deminiere JM, Le Moal M, Simon H (1989). Factors that predict individual vulnerability to amphetamine self-administration. Science 245: 1511-1513.

Post RM, Weiss SR, Pert A (1987). The role of context and conditioning in behavioral sensitization to cocaine. Psychopharmacol Bull 23: 425-429.

Robbins TW (1976). Relationship between reward-enhancing and stereotypical effects of psychomotor stimulant drugs. Nature 264: 57-59.

Robinson TE, Berridge KC (2003). Addiction. Ann Rev Psychol 54: 25-53.

Stewart J, Badiani A (1993). Tolerance and sensitization to the behavioral effects of drugs. Behav Pharmacol 4: 289-312.

Stewart J, Vezina P (1988). Conditioning and behavioral sensitization. In: Kalivas PW, Barnes CD (eds). Sensitization in the Nervous System. Telford Press: Caldwell, NJ. pp 207-224.

Sutton MA, Beninger RJ (1999). Psychopharmacology of conditioned reward: evidence for a rewarding signal at D1-like dopamine receptors. Psychopharmacology 144: 95-110.

Taylor JR, Horger BA (1999). Enhanced responding for conditioned reward produced by intra-accumbens amphetamine is potentiated after cocaine sensitization. Psychopharmacology 142: 31-40.

Taylor JR, Jentsch JD (2001). Repeated intermittent administration of psychomotor stimulant drugs alters the acquisition of Pavlovian approach behavior in rats: differential effects of cocaine, D-amphetamine and 3,4-methylenedioxymethamphetamine ('Ecstasy'). Biol Psychiatry 50: 137-143.

Taylor JR, Robbins TW (1984). Enhanced behavioural control by conditioned reinforcers following microinjections of D-amphetamine into the nucleus accumbens. Psychopharmacology 84: 405-412.

Tilson HA, Rech RA (1973). Conditioned drug effects and absence of tolerance to D-amphetamine induced motor activity. Pharmacol Biochem Behav 1: 149-153.

Tirelli E, Terry P (1998). Amphetamine-induced conditioned activity and sensitization: the role of habituation to the test context and the involvement of Pavlovian processes. Behav Pharmacol 9: 409-419.

Tomie A (1996). Locating reward cue at response manipulandum (CAM) induces symptoms of drug abuse. Neurosci Biobehav Rev 20: $505-535$.

Vezina P, Giovino AA, Wise RA, Stewart J (1989). Environmentspecific cross-sensitization between the locomotor activating effects of morphine and amphetamine. Pharmacol Biochem Behav 32: 581-584.

Vezina P, Lorrain DS, Arnold GM, Austin JD, Suto N (2002). Sensitization of midbrain dopamine neuron reactivity promotes the pursuit of amphetamine. $J$ Neurosci 22: $4654-4662$.

Wise RA, Bozarth MA (1987). A psychomotor stimulant theory of addiction. Psychol Rev 94: 469-492.

Wolf ME, Dahlin SL, Hu XT, Xue CJ, White K (1995). Effects of lesions of prefrontal cortex, amygdala, or fornix on 
behavioral sensitization to amphetamine: comparison with $N$-methyl-D-aspartate antagonists. Neuroscience 69: 417-439.

Wolterink G, Phillips G, Cador M, Donselaar-Wolterink I, Robbins TW, Everitt BJ (1993). Relative roles of ventral striatal D1 and D2 dopamine receptors in responding with conditioned reinforcement. Psychopharmacology 110: 355-364.

Wyvell CL, Berridge KC (2001). Incentive sensitization by previous amphetamine exposure: increased cue-triggered 'wanting' for sucrose reward. J Neurosci 21: 7831-7840. 